\title{
Leitura Estratégica: articulando reflexão e ensino para uma prática leitora significativa
}

\section{Diane Blank Bencke}

Mestranda em Letras do Programa de Pós-

Graduação em Letras da Unisc (Universidade de

Santa Cruz do Sul), na área de concentração em Leitura e Cognição. Professora de Língua Inglesa e Língua Portuguesa da rede municipal de

Venâncio Aires (RS). E-mail:

dianebl@terra.com.br 

PAULIUKONIS, Maria Aparecida Lino; SANTOS, Leonor Werneck dos (Orgs.). Estratégias de leitura: texto e ensino. Rio de Janeiro: Lucerna, 2006.

A obra Estratégias de leitura: texto e ensino, lançada em 2006 pela editora carioca Lucerna, é uma coletânea de doze artigos de diversos lingüistas brasileiros sobre a leitura, em abordagens que, segundo comentário de contracapa de Luiz Carlos Travaglia, constroem, em seu conjunto, uma ponte entre a pesquisa lingüística e a prática pedagógica relativa ao ensino e aprendizagem de línguas, ao analisar estratégias de construção textual em gêneros textuais diversos e propor atividades de leitura e compreensão com base em estratégias.

O primeiro artigo, "O texto: suas formas e seus usos", de José Carlos de Azevedo (Uerj), inicia conceituando a língua e mencionando os estudos de Jakobson, da Teoria da Comunicação, e a taxionomia de funções da língua proposta por Halliday (1976), sem, contudo, contrastar as visões teóricas. Em seguida, o autor destaca a relevância da forma para a caracterização dos gêneros textuais através da apresentação de uma receita culinária, um anúncio publicitário, uma fábula e uma anedota. Em um segundo momento, os tipos textuais narração, descrição, dissertação, diálogo e injunção - e seus fundamentos lógicos são apresentados, sendo os tipos textuais ilustrados a partir de fragmentos dos gêneros textuais anteriormente citados, com exceção do diálogo.

Em conjunto, Cilene da Cunha Pereira, Maria da Aparecida Meireles de Pinilla, Maria Cristina Rigoni Costa e Maria Thereza Indiani de Oliveira (UFRJ), em "Gêneros textuais e modos de organização do discurso: uma proposta para a sala de aula", realizam um exaustivo debate sobre gêneros textuais, funções, critérios de categorização e estruturação, relacionando-os aos modos de organização do discurso. Utilizando um modo de apresentação muito elucidativo, através de tabelas, exemplos e análise consistente, a parte relacionada ao ensino exibe modelos 
de cinco gêneros textuais em atributos como objetivo do gênero, da organização expositiva, ponto de vista do enunciador e recursos lingüísticos utilizados pelo autor, o que demonstrou profundidade no tratamento teórico dos gêneros e tipos textuais e, concomitantemente, uma inovadora abordagem pedagógica.

Leonor Werneck dos Santos, doutora em Língua Portuguesa pela UFRJ e uma das organizadoras do presente livro, em "Práticas de linguagem e PCN: o ensino de língua portuguesa", afirma a necessidade de o ensino de língua portuguesa permitir que seus usuários pensem $a$ e em sua língua, conforme Souza (1984). Essa ideologia de ensino de língua portuguesa orienta a autora na elaboração de três propostas de atividades de leitura e compreensão textuais de direta utilização didática, cada uma trabalhando diferentes gêneros.

Edila Vianna da Silva (UFF) e Regina Célia Cabial Argelim (UFRJ) medeiam reflexões sobre a variação lingüística através do artigo "O ensino de língua portuguesa: da heterogeneidade lingüística à prática em sala de aula”, no qual afirmam que o papel docente na escola é ensinar a variedade lingüística padrão, sem desconsiderar a legitimidade de todas as variantes e a interferência de fatores de natureza sociocultural na sua determinação. $\mathrm{Na}$ parte didática, apresenta-se uma proposta de atividade com três tipos de carta. Apesar de diferenciar-se ao estar centrada em um gênero textual e contemplar vários componentes de variação lingüística, nenhuma proposta traz elementos da fala e da escrita específicos de uma região, cuja inclusão de peculiaridades seria pertinente ao estudo desenvolvido no artigo.

Como o título já sugere, o fio condutor do artigo "Trabalhando a leitura em sala de aula", de Angela M. S. Corrêa e Tânia Reis Cunha, docentes da UFRJ, propicia um instrumento para o ensino da leitura com base em traços discursivos do texto. Partindo de uma visão de leitura para além de uma atividade meramente decodificadora, as autoras criam um questionário que explora a notícia em 
suas propriedades gráficas, marcadores temporais e espaciais, relações sintáticas, coesivas, temáticas e discursivas e, em seguida, aplicam-no à análise de uma reportagem e de uma fábula. Essa aplicação de um instrumento de leitura para textos de diferentes naturezas - literário e não-literário —, realizando-se os ajustes necessários em algumas questões, mostra-se uma das contribuições de maior valor dessa produção científica.

Tematizando uma das funções da linguagem de maior uso cotidiano - a da argumentação — , Sigrid Cavazzi e Cristiane Guimarães, pesquisadoras da UFF, desenvolveram, no artigo "O ensino da argumentação nas aulas de língua portuguesa: três propostas de trabalho", a exploração de três propostas de ensino de técnicas argumentativas relacionadas a níveis de complexidade da frase, do parágrafo e de ensaio, destinadas a alunos do ensino médio. A primeira está alicerçada na identificação de índices do "dispositivo argumentativo" (DIAS, 1998); a segunda direciona-se à análise de estratégias argumentativas; e, por fim, a terceira contempla tipos de argumento. No entanto, falta ao conjunto das propostas a proposição de uma tarefa capaz de concatenar os três níveis de compreensão argumentativa.

Operadores argumentativos, expressão cunhada por Ducrot na semântica argumentativa, incide sobre marcas lingüísticas que direcionam a argumentação: eis o alvo da proposta de Lúcia Helena Martins Gouvêa (UFRJ) em "Operadores argumentativos: uma ponte entre a língua e o discurso". A argumentação pode estar implícita ou explícita, o enunciador pode ser individual ou coletivo, as proposições podem ser verdadeiras ou falsas - conceitos, como esses, estão demonstrados por meio de trechos de uma crônica. Na continuação, são explicados e exemplificados os argumentos dos tipos "fatos", "dados" e "raciocínios", relacionando-os aos modos de organização do discurso e também à tipologia argumentativa apresentada por Koch (2004). Já quanto ao plano de trabalho pedagógico, mesmo sem ter sido sugerido nenhum 
texto em particular, a atividade didática elaborada é consistente, abrangendo aspectos como identificação da proposta, classificação dos argumentos, dos operadores argumentativos, entre outros.

Oferecer subsídios para uma leitura crítica da propaganda é o intuito de Maria Aparecida Lino Pauliukonis, doutora em Língua Portuguesa pela UFRJ e também organizadora desse livro, em "Estratégias argumentativas no discurso publicitário". Os textos midiáticos estabelecem um contrato comunicativo marcado pelo uso de estratégias argumentativas, por sua vez, baseadas em três princípios: percepção, relevância e apreensão. Empregando cinco textos propagandísticos embasados no topos "a mulher é sempre a guardiã do bemestar da família", analisam-se as estratégias lingüísticodiscursivas de configuração da imagem do produto e do destinatário. Ao promover uma leitura consciente, leitura pelas entrelinhas do texto publicitário, esse artigo também cumpre um papel social para com os educandos, promovendo o reconhecimento e a problematização dos lugares sociais ideologicamente construídos e os mecanismos de sedução que caracterizam esse gênero.

Servindo-se de abordagens sobre o discurso publicitário, Rosane Santos Mauro Monnerat (UFF) enfoca as modalidades enunciativas e suas representações na publicidade em "Atos (trans)locutivos no discurso da publicidade - faces e máscaras". O artigo caracteriza o contrato de comunicação, o anunciante, o sujeito-alvo duplo e os modos discursivos, o ethos, o pathos e o logos. $\mathrm{Na}$ articulação teoria e prática, os modos de organização do discurso e os tipos discursivos para o texto publicitário são citados consoante a tipologia de Charaudeau (1983). A definição das modalidades dos atos alocutivos, elocutivos e delocutivos e a exemplificação através de textos de propaganda conferem um grau de completude ao artigo e tornam mais acessível a apreensão de um aspecto complexo da linguagem — os atos de fala -, mesmo que não se apresente uma proposta de trabalho 
efetiva, apenas comentários analíticos que podem guiar o docente na elaboração de instrumentos de leitura para o enfoque desse assunto.

Somente por esclarecer as diferenças entre polifonia e intertextualidade, já há uma importante razão para a leitura de "Polifonia e inter-textualidade: as vozes da notícia", de Lygia Maria Gonçalves Trouche (UFF). De grande utilidade conceitual, a autora define e relaciona polifonia e intertextualidade, marcando os tipos de intertextualidade e apresentando os componentes de qualquer cena enunciativa. Além disso, Lygia explica e exemplifica, dentro do gênero "notícia", alguns índices de adesão e não-adesão do locutor. Destaque-se que esse artigo fomenta um processo de leitura e compreensão nãoingênuo, reconhecedor dos sinais enunciativos que assinalam a opinião do emissor, comprometendo a pretensa neutralidade da linguagem jornalística.

Os estudos lingüísticos, de maneira geral, muito pouco se ocupam da investigação dos nominativos humanos. Contribuindo para os estudos sobre esse tópico, Cláudio Cezar Henriques (Uerj, Unesa e ABF), em "Léxico e discurso: epítetos fóricos", conceitua e classifica os nominativos humanos em níveis de vinculação e estágios de sinonimização, funções gramaticais e papéis lingüísticos, tornando a explicitação do papel coesivo dessa unidade lingüística o principal aspecto positivo do artigo.

Que fatores estão envolvidos na relação entre interpretação e sentido? A resposta a essa pergunta está desenvolvida na produção científica "Interpretação e sentido", de Fernando Afonso de Almeida (UFF), que ressalta o papel de protagonista do sentido no processo de comunicação. No prisma de Almeida, comunicar por via da linguagem é um processo de elaboração e compreensão de indícios, do qual participam o cálculo interpretativo e o encadeamento. Os fatores envolvidos nas trocas lingüísticas aqui foram esparsamente exemplificados através de trechos do gênero "diálogo"; assim, o 
autor poderia ter enfocado melhor o fenômeno dos tropeços interpretativos, cuja conscientização pode contribuir para o desenvolvimento da competência metacomuniciativa.

André Valente (Uerj/Facha) encerra o presente livro com o artigo "A intertextualidade nos discursos midiático e literário", apresentando os princípios da textualidade e discutindo classificações de intertextualidade. Também caracteriza a polifonia e a interdiscursividade em suas tipologias de citação e alusão. Com uma abundância de exemplos em diferentes gêneros midiáticos literários e não-literários, esse artigo é mais uma evidência da heterogeneidade discursiva, apropriação e fusão de gêneros, e da riqueza lingüística de sentidos que os discursos literário e não-literários carregam.

Empregando uma linguagem acessível, de cunho explicativo, a leitura de Estratégias de leitura: texto e ensino é agradável e útil do ponto de vista do professor de língua portuguesa, que aperfeiçoa seu fazer pedagógico quanto a subsídios, técnicas e metodologias de leitura e compreensão textuais, promovendo o enriquecimento da formação do estudioso da linguagem no que concerne aos aspectos lingüístico-discursivos envolvidos na leitura. Façase aqui a ressalva de que esse livro é destinado a professores de todas as disciplinas, pois todos eles são mediadores de leitura. Por constituírem formas de organização comunicativa dos seres humanos, os gêneros textuais permitem propostas de leitura e compreensão com um enfoque inter e transdisciplinar.

Voltadas as reflexões às situações de ensino e aprendizagem da leitura em língua materna, especialmente no caso de estudantes do ensino médio e de graduandos de letras, fica aqui a sugestão de realizar um trabalho de semelhante natureza na área do ensino de língua estrangeira. Analogamente, talvez fosse importante explicitar as contribuições da lingüística e da psicolingüística no território do ensino de línguas, referenciais teóricos que, apesar de guiar esse trabalho, pouco estão explicitados. 
Mesmo que alguns artigos tenham realizado uma abordagem mais superficial ou enxuta no momento de propor atividades de leitura, há uma coerência interna na obra, já que todos os artigos partem de uma concepção de leitura como atividade significativa de produção de sentidos e de reflexão acerca da linguagem. A multiplicidade de enfoques e abordagens de aprendizado da leitura, com base em diferentes estratégias e diferentes gêneros textuais, em Estratégias de leitura: texto e ensino, é evidência das manifestações plurais do ser lingüístico (que é o ser humano) e do seu olhar leitor sobre essas manifestações. 


\section{Referências}

CHARAUDEAU, Patrick. Langage et discours. In:

Élements de semiolinguistique (théorie et pratique). Paris:

Hachette, 1983.

DIAS, Clementina da Silva. Redações de vestibular. 1998.

Dissertação (Mestrado em Língua Portuguesa)-Universidade

Federal do Rio de Janeiro, Rio de Janeiro, 1998.

HALLIDAY, M.A.K. Estrutura e função da linguagem. In:

LYONS, John. Novos horizontes em lingüística. São Paulo:

Cultrix, 1976.

KOCH, Ingedore. A inter-ação pela linguagem. 9. ed. São Paulo: Contexto, 2004.

SOUZA, Luiz M. de. Por uma gramática pedagógica. 1984. Tese (Doutorado em Lingüística)-Universidade Federal do Rio de Janeiro, Rio de Janeiro, 1984. 